\title{
O CORPO EM FRONTEIRAS: PERFOMANCES EXCLUDENTES NO UNIVERSO ESCOLAR: UMA NARRATIVA ETNOGRÁFICA
}

\author{
Marcio Rodrigo Vale Caetano \\ Paula Almeida de Castro
}

\section{RESUMO}

As performances excludentes são apresentadas, neste artigo, através da narrativa etnográfica deslocando o não-lugar do corpo na fronteira interativa do universo escolar. Esta interação apresenta-se nas aulas de História com a aluna Tereza e seus processos de aprendizagem marcados pela estigmatização latente daqueles que permanecem nos espaços educativos sem que dele prescindam suas regras. A narrativa nos conduz por um ano letivo e por possibilidades avaliativas na perspectiva de uma Educação que se pretende inclusiva na sua função formadora de alunos e professores em exercício de sua prática.

Palavras-chave: Performance; Exclusão; Estigma; Etnografia.

\section{THE BODY IN BORDERS: EXCLUSION PERFORMANCES AT SCHOOL UNIVERSE: AN ETHNOGRAPHIC NARRATIVE}

\begin{abstract}
The exclusion performances are presented in this paper through ethnographic narrative moving the non-place of the body in interactive boundary of the scholar universe. This interaction is presented in History classes with Tereza student and their learning processes noticeable beside latent stigmatization of those who remain in educational spaces without abstain its rules. The narrative takes us through a school year and evaluative possibilities with a view to Education intended to be inclusive in its developmental role of students and teachers in their own practice.
\end{abstract}

Keywords: Performance. Exclusion. Stigma. Ethnography.

Apresentam-se, neste artigo, a experiência docente estabelecida na perspectiva da interação com o aluno - sujeito escolar - e a descrição etnográfica de pesquisa que permite desenhar esse registro para o leitor. Esta interação se dá entre o professor de História, sua turma de $6^{\circ}$ ano e os demais atores que circulam o cotidiano escolar. A narrativa desencadeada na prática docente é registrada, sobretudo, no não-lugar que uma aluna - sujeito da exclusão ocupa no interior da escola e da sala de aula.

Foram participantes dessa pesquisa alunos do $6^{\circ}$ ano de uma escola privada do município do Rio de Janeiro. Na escola procedeu-se a coleta dos dados, a partir da observação participante das aulas de História, no período de um ano letivo. Destaca-se que os nomes e dados que pudessem identificar os sujeitos e a instituição foram alterados por razões éticas, sem prejuízo do processo de análise dos dados e da apresentação dos resultados.

A abordagem etnografia crítica e a colaboração em pesquisa, oferecem subsídio teóricometodológico à pesquisa, sobretudo por tratar-se de temática relacionada à Educação, lançando luz para a apreensão do conhecimento e do entendimento do sujeito pesquisado sobre seus "fazeres diários". É a etnografia, portanto, uma ferramenta importante para fazer sentido sobre a realidade estudada. Enquanto preponderantemente derivada dos paradigmas interpretativo, ecológico e interacionista-simbólico, a etnografia pode conferir à pesquisa um aparato teórico que vai além do mecanismo de fazer pesquisa, isto é, de uma metodologia científica derivada da pesquisa qualitativa. 
O processo de derivar significado do material de pesquisa é quando a figura do pesquisador e a do professor passam a oferecer explicações sobre sua vida pessoal, escolar e dos processos interativos por eles vivenciados na escola e na sala de aula. Passou a ser buscado, ainda, as explicações dos participantes, tomados enquanto sujeitos escolares que possuem um conhecimento privilegiado sobre suas práticas diárias em sala de aula e na escola, a partir das produções de sala de aula. Neste sentido, os sujeitos escolares foram os principais autores das interpretações realizadas, sendo considerados possuidores de seus próprios sentidos sobre as formas de pertencimento na vida escolar. No mesmo processo colaborativo, professor e pesquisadores resignificaram as tarefas e ações evidenciadas no cotidiano da escola.

Para o pesquisador, o conhecimento adquirido pela etnografia ultrapassa a gênese da construção acadêmico-intelectual de buscar neutralidade, cientificidade objetiva e a percepção particular sobre o outro. Na pesquisa crítica colaborativa, a elaboração reflexiva sobre o existir se faz necessária por ambos os grupos de atores, pesquisadores e pesquisados. Enquanto atribuidora de sentido às atividades cotidianas, a etnografia impõe ao pesquisador uma posição de intérprete privilegiado dos sujeitos que doam sentido sobre as suas vidas. Ao participante, a etnografia propicia um distanciamento da realidade diária que muitas vezes lhe é invisível pelo caráter rotineiro das ações. Isto oportuniza a reflexividade e relativiza o sentido imediato dado a ação. Numa perspectiva freireana isto significa "colocar em destacado" as questões diárias para refletir sobre elas problematizando-as. Em colaboração com os pesquisadores, ao professor é possibilitado desenvolver, além do sentido mais frequente que já possui sobre essas ações. Neste momento, um novo sentido, mais elaborado e problematizado, é criado dando uma dimensão crítica à realidade e possibilitando a sua reelaboração significativa.

Nessa derivação etnográfica do cotidiano da prática docente, os "fazeres diários" foram revisitados através do estudo de caso etnográfico da aluna Tereza que destacou-se dentre os demais sujeitos da turma, por ser multirepetente, conhecida dos demais professores por características psiquiátricas não diagnosticadas e que derivavam em condutas estigmatizantes por parte da comunidade escolar. A narrativa que se segue apresenta ao leitor o cenário, familiar, mas que tornaremos estranho, para que a cada seja possível novos olhares, novas leituras. Toma-se na primeira pessoa a narrativa etnográfica da experiência escolar e em terceira nas que fazem referência às interpretações colaborativas entre os autores.

\section{A narrativa: registros da experiência docente}

A sala, os alunos, as portas, os corredores, os conselhos de classe, a mesa redonda da biblioteca, o quadro, o giz, a direção, as falas, os silêncios, os sentimentos e a memória docente são partes desse universo narrado e analisado.

O final de mais um ano letivo se aproxima e com ele os anseios de alunos, alunas e professores ecoando por todos os lados quanto aos resultados que desencadearão os arranjos para o futuro. $\mathrm{O}$ andamento especulativo se refere justamente sobre os possíveis "retidos" aqueles que serão reprovados. Ao toque do sinal, é hora do recreio, a escola corre pelos corredores e, em desespero, alunos e alunas descem as escadas sempre olhando pra trás para não sofrerem as sanções de seus atos: é necessário ficar atento, porque a fala áspera da autoridade não é benevolente. As professoras e os professores estão caminhando para o refeitório onde, em meio ao copo de café, narram com o corpo e as vozes os fatos ocorridos em sala de aula.

Em meio às experiências narradas, uma voz dissonante dá início à pergunta, "Professor quais são os alunos que possivelmente ficarão retidos na $6^{a}$ série?" Sem ainda ter desenhado o quadro solicitado e tendo a consciência de que não queria falar sobre as dinâmicas da sala de aula, respondo sem meias palavras, "ainda não sei". Uma professora citou o nome de cinco e o 
que me espantou foi Tereza estar entre os citados, o que antes era um destelho, agora passou a direcionar minha atenção, como se discordasse daquilo.

Tereza foi apresentada na primeira semana de aula. Chegamos ao mesmo horário no primeiro dia de aula e uma professora da disciplina de Língua Portuguesa, reconhecendo nas minhas marcas, a inexperiência da docência que outrora não se compararia com seus 40 anos de carreira, deu-me, em um ato de plena solidariedade, o quadro geral da escola na qual ela leciona há mais de 20 anos. Caminhando pelo corredor escuro, que de um lado dá acesso à capela e de outro à escada que permite se chegar ao pátio, a professora apontou as três turmas em que iria lecionar a disciplina de História.

Atrás da porta, olhando pelo quadrante em vidro que permite ver por fora sem que os mesmos consigam nos ver de dentro, a professora em frente à turma 61 destacou a boa qualidade da turma: "Você irá gostar da turma, são excelentes alunos. Ah! Já ia esquecendo, está vendo aquela aluna no canto direito da turma, na primeira fila?" _ "Não!" - espondi sem muita demora, afinal entre a fila e a porta tinha um armário que não permitia ver justamente essa parte da turma. _."Tudo bem, você quando entrar fique atento a essa aluna, o nome dela é Tereza, ela está conosco há muitos anos. É ótima, não dá trabalho algum, não conversa, realiza as atividades, mas infelizmente sofre de retardamento mental". De imediato ignorei a informação, afinal era meu primeiro dia de aula e devido ao armário não conseguia ver Tereza. Aliás, acredito que o fato de não dar trabalho, como foi destacado pela professora, levou-a para aquele lugar da sala, à medida que ela não precisava ser vista pelo olhar do quadrante de vidro da porta.

Os meses se passaram e, observando Tereza, não foi difícil perceber o porquê da nomeação que lhe foi dada: a voz lenta com difícil dicção, os braços, que insistiam em se movimentar com a velocidade dos cílios. Todos os gestos demarcavam a vagarosidade com que opinava nas aulas. A turma cheia, vozes aos gritos, adolescentes que insistiam em ignorar o pedido de silêncio, o quadro me obrigava a descer à altura dos alunos e alunas, que estavam sentados, a fim de puder ouvir suas indagações. Era comum ir ao encontro da pergunta e escrevê-la no quadro com o nome do autor para divulgá-la à turma.

Em meio aos temas das aulas sobre as Civilizações da Antiguidade, aproveito para utilizar o documentário "Mesopotâmia - As grandes civilizações", de Robert Gardner, produzido para veiculá-lo no canal pago "Discovery Cilivization". A estratégia pedagógica servia de "pano de fundo" para discutir a importância da escrita na regulação e controle das relações com os Códigos de Hamurábi.

Com o debate provocado pelo documentário, Tereza chamou-me para comentar a profissão de sua mãe, "Professor, professor!" _ "Só um minuto Tereza", disse eu. "Diga meu anjo", respondi logo após concluir o que estava explicando. "Minha mãe é advogada", anunciou Tereza. Com essa notícia, ouve-se uma voz ao fundo da sala _ "Ela não sabe o que está falando, professor". A turma inicia um o que poderíamos descrever com uma orquestração desqualificadora do comentário de Tereza. Era a oportunidade necessária para desencadear os risos coletivos. De imediato, talvez estimulado por minhas experiências que, como já sinalizei, estão sob a guarda das minhas memórias, respondi: "Quem não sabe é você. Ela está comentando, coisa que você nunca faz". Sinalizamos, inclusive, a menção que Dubet (1997) faz sobre ao professor ser necessário fazer um "golpe de estado" com seus alunos em sala de aula.

O silêncio entrou na sala de aula, os alunos perceberam o tom que utilizei para encerrar a orquestração em torno da aluna. Finalizei minha fala, com uma voz dura, uma cara amarrada e com a autoridade outorgada pelo posto que ocupava:

Quero que vocês saibam de uma coisa, não admito, não admito mesmo, seja com quem for, não admito brincadeiras que provoquem tristeza no outro, 
não existe alguém no mundo que ame ficar triste, acredito que nessa sala não haja exceção, logo não entendo por que querer deixar o outro triste, todos vocês são importantes, independente de serem diferentes ou semelhantes a mim. Que o que houve agora não se repita, pensem antes de falar, se o que for dito for provocar tristeza no outro, não o diga. Estamos conversados? (Professor de História - turma de $6^{\circ}$ ano).

Apesar da pergunta ter finalizado a minha fala, o silêncio permaneceu toda a aula, os olhos dos alunos não conseguiam me acompanhar pela sala, suas cabeças estavam abaixadas como se todos tivessem cometido um grande erro e a qualquer momento a sentença seria tomada.

No dia seguinte, andando pelo corredor, Tereza bate em minhas costas entregando-me, com uma voz trêmula, braços e cílios agitados, uma carta. Disse a ela que leria em casa. Quanto à turma, esta retornou à regularidade: barulhos, vozes, gritos e objetos sendo lançados pelos ares vez por outra.

Com a caneca de café e sentado no sofá corrigindo os trabalhos, vejo a carta de Tereza, foi quando interrompi o que estava fazendo para poder lê-la:

Dia 25 de outubro de 2014.

Para o professor de História

História: vivendo e aprendendo

Gente é diferente de bicho. Bicho já nasce sabendo quase tudo. Todas as coisas ficam guardadas dentro dele, bem sabidas. Quando ele precisa, aparecem. Por exemplo, ninguém ensina um cachorro a nadar, ensina? Eu nunca vi. Ele entre na água e sai nadando. Mas gente é muito diferente. Gente, quando nasce, só sabe mamar, chorar, fazer xixi e pumpum. Daí, gente precisa de professor de tudo quanto é coisa. Umas coisas, o pai, a mãe e a família ensinam, sozinhas. Outras coisas, a gente precisa de um professor de verdade.

Na escola, tem tantos e tantos professores que, se eu contar, ninguém acredita. Tem um professor para cada coisa, História, Geografia, Matemática, Educação Física...

Existe professor de tudo no mundo. Logo que se inventa uma coisa nova, aparece um professor para ensinar. Veja lá o caso do computador. Mal inventaram os computadores, e já existem os cursos de computação. Eu mesma, quando crescer, vou fazer um curso desses.

Agora, eu não sei quem é que foi primeiro professor do mundo. E quem ensinou tudo a este professor? Eu acho que o primeiro aprendeu sozinho ou foi o inventor das coisas que ele mesmo ensina. Isso eu não sei direito. Não sei, não. Mas o bom do professor é que ele quer ensinar tudo, tudinho. Quanto mais a gente aprende, mais ele gosta. Fica contente, dá nota boa. Não é como uma amiga da minha mãe, que ensinava as receitas de doce pela metade para o doce dela ficar melhor de que o da minha mãe.

Professor já nasce feito, perfeito. Tem de ter jeito de professor, paciência de professor, alma de professor e coração de professor. Tem, sim (para caber todos os alunos dentro). Senão, ele perde a paciência e desiste quando encontrar uns meninos levados, como certos amigos que eu tenho. É o que eu acho!

Beijos da sua aluna que te ama de verdade, Tereza $n^{\circ} 37$.

(Carta da aluna Tereza $-6^{\circ}$ ano direcionada ao professor de História). 
Era o primeiro texto com temática livre da Tereza e a leitura do mesmo impressiona pelo fato de não haver erros. De imediato remontamos que seu nome foi citado pela professora de português para ser possivelmente retida na $6^{a}$ série. Na semana seguinte, o texto foi levado para que os/as demais colegas que lecionam para Tereza pudessem ler. Todos ficaram encantados com o texto, no entanto, Tereza ainda estava na lista dos retidos, afinal esse ano era o ano de sua retenção. Os professores, diante do "diagnóstico" de seu "retardamento mental", avaliaram que era melhor Tereza ficar na escola a ir para a escola pública, onde possivelmente seria abandonada. Realidade esta que foi apontada pelas professoras que possuíam experiência na rede estatal de ensino. No entanto, para não colocar em dúvida a seriedade da escola particular, os professores fecharam que a conclusão de cada ano letivo seria em dois, independente de seu rendimento, já que desconsideravam a possibilidade de Tereza acompanhar o rendimento da maioria da turma.

\section{Corpo, modos de subjetivação e exclusão}

O que é, de fato, importante, nos processos avaliativos dos sujeitos escolares? A relevância de permanecer enquanto corpo físico no espaço da sala de aula não implica em aquisição e produção de conhecimentos escolares. Esse quadro nos leva a refletir sobre a estrutura das sociedades ocidentais e no seu interior, a brasileira. Orientada pelo discurso modernista, construiu inúmeras classificações que legitimaram a sua divisão hierárquica. Nesse sentido, definiram-se meios de categorizar os indivíduos em posições e condições "estigmatizadas", preestabelecendo-se requisitos comportamentais. O quadro é confirmado por Goffman (1988), no qual, as atitudes classificatórias seriam usadas como atributos profundamente depreciativos. Rotina que também se materializa nas inúmeras relações que se estabelecem no cotidiano escolar. No entanto, diferente das relações entre adultos nas quais muitos dos símbolos são conhecidos e/ou vivenciados, a escola por seu papel, tem como agentes de sua interdição crianças e adolescentes que não possuem os elementos necessários e legais ${ }^{2}$ para sua defesa diante das classificações atribuídas.

Estigmar um sujeito significava para os gregos, conforme indica Goffman, a referência a "sinais corporais com os quais se procurava evidenciar alguma coisa de extraordinário ou mau sobre o status moral de quem os apresentava" (p.5). Com estes sinais, estigmas, os ladrões, escravos e traidores eram identificados em locais públicos pelas marcas feitas com fogo e mantidos à distância das pessoas moralmente aceitas pela sociedade. Esta mesma perspectiva, pode ser adotada pelos estigmas atribuídos àqueles que fogem às regras de conduta moral estabelecidas. O diferente, o que era marcado, passa agora a carregar sob si a marca indelével da exclusão, por ser reforçada pelas instituições sociais e seus sujeitos ditos morais e normais. Entendemos que as performances do campo simbólico demarcam os mecanismos de exclusão que se operam nas práticas escolares, tal como revelado na narrativa sobre Tereza.

De acordo com Velho (1990), o comportamento desviante, materializado na representação social, se não for reconhecido e analisado de forma crítica e fundamentada, permanecerá e se consolidará como elemento cotidiano de classificação. A idéia de desvio implica a existência de um comportamento ideal, que expressaria uma harmonia com as exigências do funcionamento do sistema social. Portanto, a idéia de desvio parte do pressuposto comparativo de pessoas pré-definidas como saudáveis. ... "não existindo desviantes, mas sim, uma relação entre atores que acusam outros atores de estarem consciente ou inconscientemente quebrando, com o seu comportamento, limites e valores socioculturais" (VELHO, 1990, p. 139).

Os desviantes e os excluídos estão invisibilizados pelos mecanismos impostos pelos valores socioculturais, observados, sobretudo, nas escolas. É a chamada desqualificação do 
indivíduo, como menciona Foucault (2002) ao explicar o rigoroso policiamento com que eram mantidas as pessoas que eram consideradas perigosas para a sociedade. Foucault (idem) explica que "não se trata de uma exclusão, trata-se de uma quarentena. Não se trata de expulsar, trata-se ao contrário de estabelecer, de fixar, de atribuir um lugar, de definir presenças controladas" (p.57). O autor nos ajuda a refletir sobre o cenário escolar de Tereza ao fazer referência ao controle imposto àquele que ao ser considerado portador de alguma mazela, passa a ser monitorado para que não contamine outras pessoas com a doença que possui. A exclusão ocorre pela delimitação do espaço a ser ocupado pelos corpos estigmatizados tornando, assim, invisível à sociedade, o sujeito do estigma.

No interior desse cenário está o fato de definir e classificar sujeitos ou grupos escolares considerados fora dos padrões estabelecidos pela cultura escolar hegemônica. Como resultados históricos, as classificações são também frutos de pensamentos e ideias que se materializaram nos olhos da "ciência" aliada à construção do próprio Brasil. A classificação de "portadora de retardamento mental" foi dada a Tereza por laudo médico e que, portanto, toda e qualquer ação junto a Tereza seria perda de tempo, afinal, ela já está sentenciada.

A aluna Tereza com suas classificações exemplifica a dinâmica cotidiana da escola que, como espaço de todos, ainda vivência a dificuldade de trabalhar as diferenças e, principalmente, entender que a diferença não está atrelada à superioridade e inferioridade de suas personagens nas inúmeras tramas que são costuradas no cotidiano das relações entre pessoas na escola. Neste sentido, a escola passa a ser "o lugar da ordem (seja qual for) segundo se distribuem elementos nas relações de coexistência, aí se acha, portanto, excluída a possibilidade, para duas coisas, de ocuparem o mesmo lugar. Aí impera a lei do "próprio"' (CERTEAU, 1994, p. 20).

Michel Certeau (1994) pode nos auxiliar a refletir o impasse criado entre a posição dos docentes e, em particular, da professora de português, que defendiam a reprovação de Tereza e a posição do professor de História que diante da carta da aluna e de suas posições sobre a função do Ensino de Português defendia a aprovação. Segundo o autor, os agentes opressivos não são capazes de determinar a forma como as leis serão consumidas pelos agentes que sofrem a opressão, por isso, esses agentes são capazes de driblar ou redimensionar as leis impostas sobre seu comportamento. Não é o fabricante que determina o uso, nem tampouco o opressor que estabelece a forma e o comportamento que suas regras irão estabelecer naqueles para os quais se destinam. Mas, o consumidor, que como receptor da ordem, estabelece a sua interpretação. Na tática o "eu" fica em segundo plano, a previsão de ações passa ser definida pelas ações que, especuladas ou não, são produzidas pelo outro: aquele que tem o poder. $\mathrm{O}$ que se pode deduzir é que mesmo que Tereza não estivesse cumprindo as exigências da professora de português, o fato é que aluna redimensionava o aprendido e com ele foi capaz de produzir um texto com todas as exigências de boa redação para estudantes do sexto ano.

Neste caso, a escola funcionou como defensora da hierarquização social, garantindo o seu papel de protetora em potencial da estrutura da sociedade ao excluir Tereza da possibilidade de aprender o que ainda não havia aprendido. Refletindo sobre esse aspecto, é que se podem observar em práticas do cotidiano escolar, a possibilidade da escola funcionar como espaço de manutenção da ordem vigente e de suas hierarquizações. Portanto, práticas excludentes balizadas nos estigmas poderiam estar no interior das hierarquizações e classificações sociais, tanto quanto nas práticas e, mais amplamente, nas ações e relações do cotidiano escolar.

Neste sentido, as expectativas estigmatizadas em torno de Tereza são as reproduções históricas dos comandos sociais a cerca daqueles que são nomeados como retardados mentais. Segundo Certeau (1994), os comandos não são meras ações descritas pela voz. Não existe voz "pura", ela é sempre determinada por sistemas de interesses. Deste modo, o que é relatado em uma sociedade escriturária (a que define as regras) é fruto do seu meio e é capaz de transformar a carne (indivíduo sem as normas coletivas ou sem inteligibilidade) em um corpo 
social, portanto, aceito ou excluído da norma. Assim, no caso de Tereza, sua escola assumiu o papel central em estabelecer o inscrito de "retardada mental" em sua carne, ao tempo que estabeleceu sua inteligibilidade social como a "reprovada".

Qual atitude tomar diante do quadro? É preciso tomar alguma atitude? As perguntas existem e as respostas são dadas, em alguns casos, pelas narrações e observações de outras experiências semelhantes. Isso permite chegar a conclusão de que a experiência alimenta o relato, este, por sua vez, utilizando-se da oralidade, é capaz de se difundir e alcançar sujeitos propícios a ouvir e armazená-los na memória, revisitando quando necessário (CERTEAU, 1994). A marca de "retardada" sobre o corpo de Tereza foi tantas vezes reiterada que assumiu lugar de verdade.

Entretanto, a relação que se constituiu entre Tereza e o professor de História possibilitou o redimensionamento das práticas de aprendizagem e através do afeto se constitui um caminho para a aluna apresentar aquilo que aprendeu da Língua Portuguesa. Como dito por Britzman (1996)

em termos de pesquisa educacional, dão a ideia de que a identidade ainda permanece presa à visão equivocada de que são dadas ou recebidas e não negociadas, quando se trata de questões de desejo, de amor e de afetividade, a identidade é capaz de surpreender a si mesma: de criar formas de sociabilidade, de política e de identidades que desvinculem o eu dos discursos da biologia, da natureza e da normalidade [...] (p. 73).

Como elemento social, a escola é também responsável pela manutenção histórica dos estigmas, seus instrumentos oficiais e ocultos fazem das representações, estigmatizadas ou não, os componentes de suas vivências cotidianas. E é na vivência diária que a potencialidade de Tereza é ignorada pela decisão que há tempo havia sido tomada. A aprovação bianual.

Um aporte teórico que nos permite analisar as conseqüências da classificação encontrase na discussão do conceito de abuso. Para Costa (2003, p.16), o termo abuso inclui prevalecerse de, aproveitar-se de, praticar excessos que causam ou podem causar dano, assim como o uso de palavras para desqualificar, ridicularizar, fazer zombarias, injúrias, insultos, usar mal ou inconvenientemente de qualquer situação de superioridade de que se desfruta e exceder-se em limites que ultrapassam o respeito pelo outro. O termo "abuso", neste sentido, inclui agressões que, mesmo não ferindo o corpo, ferem a sensibilidade, as emoções, a auto-estima e desrespeitam a identidade e singularidade da pessoa atingida, podendo causar transtornos ou desconforto emocional, que podem traduzir-se em subalternização. Tereza ficava no único lugar da sala em que não era possível sua visualização do lado de fora, afinal, seu silêncio e sua posição na turma a fazia invisível no cotidiano da sala de aula e visível no cotidiano dos conselhos de classes.

Nesse caminho, é importante enfatizar a consequência da humilhação, que pode ser tão traumática quanto os efeitos da lesão física, já que suas ações atingem a valorização pessoal, a autoconfiança e a confiança no outro. Portanto, a consequência última do abuso também é o silenciamento interferindo diretamente no bem-estar subjetivo dos indivíduos vitimizados. Há que se acrescentar que apesar de vitimizados, o papel de vítima é apenas um dos diversos lados da vivência social. Entendemos que o individuo ainda que sob o poder imperativo seja capaz de redimensioná-lo e com criatividade driblá-lo cotidianamente.

Segundo Ryff (1989), o bem-estar subjetivo inclui auto-estima, auto-aceitação, autodeterminação, relações sociais positivas, orientadas pelo respeito, qualificação e acolhimento, superação de medos, opressões e fatores de tensão que prejudicam o exercício pleno da vida. As consequências do conceito de bem-estar subjetivo são legitimadas pelos 
dados da pesquisa realizada por Rangel (1995), onde se verificou que a aprendizagem quando associada às ações de afeto a eleva ao status de prazer, condição essa que a relação educativa pode e deve proporcionar.

As imagens ancoradas na linguagem determinam os limites de sua visibilidade, são elas que ocultam as potencialidades do individuo, no nosso caso, as da Tereza. Sua produção de texto foi visto com surpresa, afinal, não havia explicação para aquele texto, seu "retardamento mental" era o limite de sua aprendizagem e seu futuro já havia sido tomado: a reprovação. No que tange à aprendizagem, a classificação dada à aluna não foi capaz de eliminar o seu desejo de participar, divulgando a profissão de sua mãe, que estava diretamente ligada ao conteúdo Os Códigos de Hamurábi -, Tereza participou e imprimiu seu lugar no espaço que também é seu: o da aula.

A dinâmica da escola com suas turmas superlotadas e as classificações já sinalizadas legitimam e garantem o preconceito social, o que obrigou Tereza a viver em um universo fechado, buscando relacionar-se somente com aqueles que permitem o espaço de sua fala, mas necessitando a todo o momento buscar sua entrada e permanência na dinâmica estabelecida na sala de aula.

O texto de Tereza provocou uma discussão no espaço da escola, os olhos antes tatuados com uma imagem permanente tiveram que ser redesenhados. A situação fragilizou as marcas afixadas a Tereza. Neste sentido, as falas que classificaram e pintaram a falta de cores que ocultaram Tereza $\mathrm{n}^{\mathbf{0}}$ 37, a fizeram, em um ato inesperado, tomar em suas mãos os pincéis, colorindo-se com cores primárias e permitindo sempre a composição de novas cores secundárias, possibilitando novas falas.

Essa pintura desenhada por Tereza em seu texto, permitiu não só desalojar os traços da imagem sem cores que estava tatuado no olhar de suas professoras, como também fez com que nós, fossemos redesenhados em nossas práticas cotidianas. Tereza Cristina foi aprovada.

\section{À guisa de conclusão e novos caminhos}

"O destino dos 'excluídos', no entanto, se define essencialmente antes que ele se fragilize" (CASTEL, 2007, p. 28).

As obras cinematográficas, neste caso o documentário "Mesopotâmia - As grandes civilizações", de Robert Gardner, produzido para veiculá-lo no canal pago "Discovery Cilivization", podem ser compreendidas e debatidas como pedagogias culturais que trabalham e desenvolvem linguagens e biografias a partir das quais vários sentidos sociais são (re) produzidos e (re) significados no recurso audiovisual e, por sua vez, pelos/as expectadores/as da obra.

A situação protagonizada pela estudante Tereza, a turma de $6^{\circ}$ ano e o professor de História nos sinaliza o quanto as obras cinematográficas são capazes de produzir interpretações infinitas e levar os sujeitos a inúmeras situações.

Interrogar as narrativas do professor nos possibilita um encontro polifônico inspirado em Bakhtin (2002). Elas se constituem como um espaço fértil à heterogeneidade enunciativa. Isso se deve ao fato que nelas os locutores retomam, implícita ou explicitamente, discursos outros, fazendo ouvir vozes e/ou os diálogos entre personagens. Nesse caminho, estamos tecendo cruzamentos e fios de experiências que ficaram momentaneamente "apagadas" no e com o tempo e foram reencontradas a partir dos diálogos estabelecidos para esse artigo. O que pretendemos realizar não é somente trazer informações sobre a prática docente, mas também, convidar à escrita todos e todas que deles se sintam personagem. A vida cotidiana oferece uma multiplicidade de momentos, lugares, espaços, situações e relações nas quais originam atos 
formativos de aprendizagens. Ela se constitui o lócus privilegiado da experiência, do saber e do conhecimento. Como Jorge Larrosa Bondía (2002), salientou "a experiência e o saber que dela deriva são o que nos permite apropriar-nos de nossa própria vida" (p. 27).

Tereza fez, com sua carta, com que nos posicionássemos sobre o lugar que ocupamos enquanto professores, pesquisadores, alunos e, em linhas gerais, sujeitos da educação brasileira. Possibilitou-nos visualizar marcas que, em suas singularidades históricas, se assemelham às inúmeras outras que são construídas nos cotidianos e espaços nos quais lutamos para nos fazermos sujeitos sociais.

Ser professor é ter uma missão alardeada por todo tipo de sujeito que no inventar de suas trajetórias levam-nos a refletir, flexionar, tensionar, reposicionar para alcançar metas inatingíveis por qualquer ser humano. Narrar a trajetória de Tereza, levou a que pudéssemos rever nossas ações e, refletindo, foi possível redimensionar e alterá-las quando necessárias.

Sobre as atribuições que acabam por estigmatizar muitas "Terezas", pode-se questionar sobre os processos formativos de alunos, alunas e de professores. Ao professor é atribuída a responsabilidade de sentir-se parte da vida escolar, cumprir sua missão de ensinar, avaliar, incluir, promover e receber diariamente seus alunos com conhecimentos que deem conta de atender a adversidade na contemporaneidade. $\mathrm{O}$ aluno, por sua vez, deve estar apto para receber o que foi idealizado para ele. É neste cenário que as concepções de professores e alunos, sobre o que venha a ser ensinar e aprender, se (des)encontram. Nestes (des)encontros é que podem surgir, como nessa narrativa etnográfica, as relações estigmatizantes que culminam em resultados de fracassos e exclusões escolares. Sobre estes olhares (des)encontrados entre aluno e professor Senna (2007) destaca que

a instituição escolar não compreende [por aluno] qualquer sujeito em formação, universalmente legitimado pela ideologia de uma educação laica. Ao contrário, a tradição social imputa à escola um sujeito ideal, um aluno perfeito, um cidadão desenhado para o modelo de cultura científica idealizada. Conceitua este aluno de forma abstrata e ideativa, sequer fronteiriça à realidade transitória e relativa dos fatos reais, manipula-o também de forma abstrata, a partir de uma ordem de causalidade fundada na lógica cartesiana, registra-o de modo a condensar racionalmente o pensamento de forma linear tanto na aquisição do conhecimento quanto na aprendizagem da escrita (p. 164-165).

Diante de uma idealização do sujeito aluno, reforça-se a ideia de que o professor precisa estar em contato com essa diversidade presente no âmbito escolar e promover junto aos seus alunos a inclusão dos mesmos através da promoção de experiências escolares orientadas para o respeito à diversidade presente nas escolas e salas de aula.

Pode-se afirmar que a escola percorreu um longo caminho no sentido de promover a inclusão da adversidade presente em nossa sociedade, contudo, há ainda muitas considerações a serem tecidas rumo a um sistema educacional que proporcione à valorização da diferença e o respeito ao diferente. O educar pelo controle suplanta a possibilidade de uma escola inclusiva, no sentido, de explicar sem compreender as diferenças e fracassos daqueles que escapam à padronização escolar, mas ainda pela incoerência entre o discurso emancipatório e a prática pedagógica elitista.

Uma escola que se pretende inclusiva, ainda precisa desconstruir-se para repensar a concepção de Educação contemporânea que possa minimizar os efeitos de práticas que, ainda, vulnerabilizam muitos alunos em seus processos de formação.

Com as análises apresentadas nesse artigo, espera-se que seja possível ampliar o debate sobre os metas da Educação inovadora que há tanto caminham na tentativa de oferecer 
condições de superação de uma realidade excludente e vulnerabilizante de seus sujeitos. A escola é ainda, o espaço de construção de conhecimento que pode oferecer mudanças nas condições sociais, econômicas, culturais e educacionais excludentes aos que nela esperam.

\section{Referências}

BAKHTIN, Mikhail. Questões de literatura e estética: a teoria do romance. 5.ed. Trad. Aurora Fornoni Bernardini et al. São Paulo: UNESP/HUCITEC, 2002.

BONDÍA LARROSA, Jorge. Notas sobre a experiência e o saber de experiência. http://www.anped.org.br/rbe/rbedigital/RBDE19/RBDE19_04_JORGE_LARROSA_BONDI A.pdf), acessado em 01 de dezembro de 2010.

BRITZMAN, D. O que é esta coisa chamada amor: identidade homossexual, educação e currículo. Educação e realidade, Porto Alegre, v.21, n.1, p.71-96, jan./jun. 1996.

CASTEL, R. As transformações da questão social. In: BÓGUS, M.C.; YAZBEK, M. Belfiore-Wanderley, (Org.) Desigualdade e a questão social. São Paulo: EDUC, 2007.

CERTEAU, M. A invenção do cotidiano: 1. Artes de fazer. Petrópolis - RJ: Vozes, 1994.

COSTA, L. S. M. da. Abuso no curso médico e bem-estar subjetivo. 2003. Tese (Curso de doutorado em psicologia social). Universidade Federal do Rio de Janeiro.

DUBET. F. Quando o sociólogo quer saber o que é ser professor - entrevista com François Dubet. Revista Brasileira de Educação. Set/Out/Nov/Dez 1997 nº 6, p. 222-231, 1997.

FOUCAULT, M. Os anormais: curso no Collège de France (1974-1975). São Paulo: Martins Fontes, 2002.

GOFFMAN, E. Estigma e identidade social In. Estigma: notas sobre a manipulação da identidade deteriorada. Rio de Janeiro: Zahar editores, 1975.

RANGEL, M. "Bom aluno: real ou ideal? 1995. Tese (concurso para Professora Titular da área de ensino-aprendizagem). Universidade do Estado do Rio de Janeiro.

RYFF, C. D. Happiness is everything or is it? Exploration on the meaning of psychosocial well being. Journal of Personality and Social Psychology. v.57, n.6, p.1069-1081, 1989.

SENNA, L. A. G. (org.). Letramento: princípios e processos. Curitiba: Ibpex, 2007.

VELHO, G. Desvio e divergência: uma crítica da patologia social. Rio de Janeiro: Jorge Zahar editor, 1989.

\footnotetext{
${ }^{1}$ Descrito como sendo a forma corriqueira de chamar a todos.

${ }^{2}$ Destaco a legalidade das ações, porque reconheço que esses alunos e alunas possuem outras ações, não vistas como legitimas que denunciam suas insatisfações diante das classificações e/ou segregações.

Recebido: fevereiro-15 Aprovado: julho-15
} 